\title{
Endoscopic ultrasound-guided pancreatic duct drainage using a novel fine-gauge electrocautery dilator
}

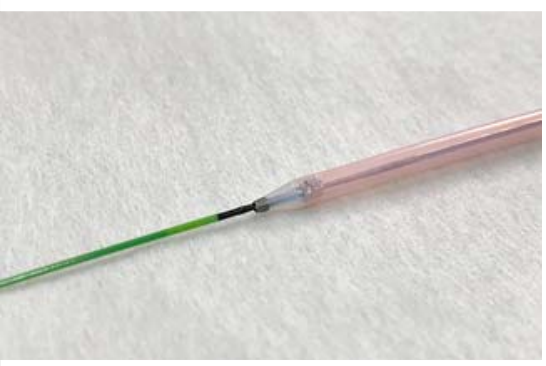

- Fig. 1 Photograph showing the novel fine-gauge electrocautery dilator (Fine025), which is wire-guided and coaxial with the 0.025 -inch guidewire. The distal end of the outer dilator has a metal tip, the top of which is $3-\mathrm{Fr}$.

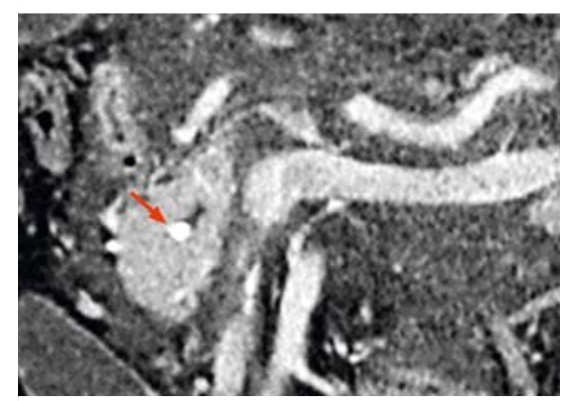

> Fig. 2 Computed tomography scan showing the stone in the main pancreatic duct at the pancreatic head (red arrow).

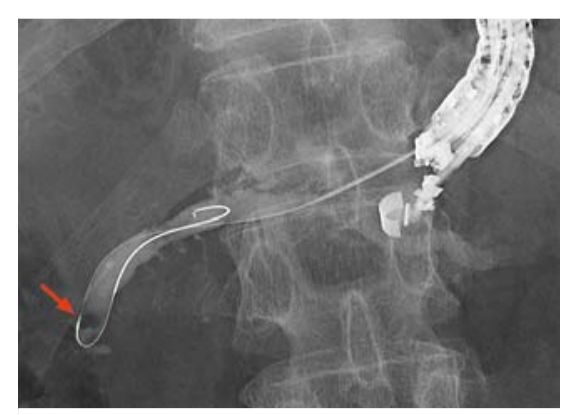

- Fig. 3 Radiographic image during endoscopic ultrasound-guided pancreatic duct drainage showing the guidewire, which had been passed through the needle into the main pancreatic duct, and the stone at the pancreatic head (red arrow).

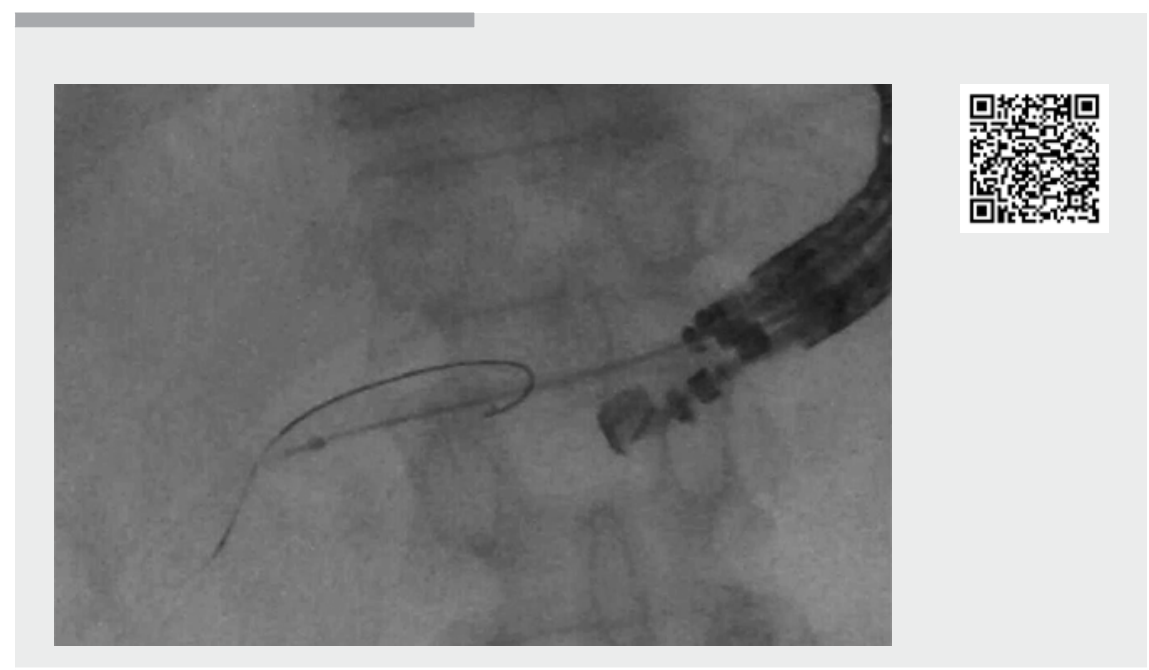

Video 1 Endoscopic ultrasound-guided pancreatic duct drainage is performed using a novel fine-gauge cautery dilator in a patient with a stricture of the pancreatic duct and stone at the pancreatic head.

Endoscopic ultrasound-guided pancreatic duct drainage (EUS-PD) is an alternative technique that can be performed after endoscopic transpapillary pancreatic duct drainage fails [1]. During EUS-PD procedures, needle tract dilation remains a challenge. Recently, a novel fine-gauge electrocautery dilator (Fine025; Medico's Hirata Inc., Osaka, Japan) has become available in Japan ( $\bullet$ Fig. 1 ). The distal end of the outer dilator contains a metal tip. The top of this tip is only $3 \mathrm{Fr}$, allowing a smaller burning effect [2]. We describe EUS-PD using this dilator in a patient with hard pancreatic parenchyma.

A 64-year-old man was admitted to our hospital for acute pancreatitis due to a pancreatic head stone ( $\triangleright$ Fig. 2 ). After the acute pancreatitis had improved using conservative therapy, endoscopic transpapillary treatment was attempted for the stone. However, a guidewire could not be passed because of the stricture of the pancreatic duct and the stone. As acute pancreatitis could have reoccurred, we decided to perform EUSPD. The dilated main pancreatic duct
(MPD) was first viewed using an echoendoscope, then the MPD was punctured using a 19-gauge needle (Sono Tip Pro Control; Medi-Globe, Rosenheim, Germany). A 0.025-inch guidewire (VisiGlide 2; Olympus Medical Systems, Tokyo, Japan) was inserted into the MPD through the needle ( $\vee$ Fig. 3 ). Dilation of the needle tract using a mechanical dilator (ES dilator; Zeon Medical Co. Ltd., Tokyo, Japan) was difficult because the pancreatic parenchyma and the MPD wall were very hard. A novel fine-gauge electrocautery dilator (Fine025) was then used. Dilation of the tract was successful; a 7- $\mathrm{Fr}$ plastic stent (Type IT; Gadelius Medical Co. Ltd., Tokyo, Japan) was placed from the MPD to the stomach ( $\vee$ Video 1 ).

This case suggests that this fine-gauge electrocautery dilator can be useful for tract dilation during EUS-PD procedures. Further studies on a large number of cases will be needed to validate its safety and efficacy.

Endoscopy_UCTN_Code_TTT_1AR_2AI 
None

The authors

Koichiro Mandai, Koji Uno, Kenjiro Yasuda

Department of Gastroenterology, Kyoto Second Red Cross Hospital, Kyoto, Japan

\section{Koichiro Mandai, MD}

Department of Gastroenterology, Kyoto Second Red Cross Hospital, 355-5 Haruobicho, Kamigyo-ku, Kyoto 602-8026, Japan Fax: +81-75-2563451

mndkchr@gmail.com

\section{References}

[1] Tyberg A, Sharaiha RZ, Kedia P et al. EUSguided pancreatic drainage for pancreatic strictures after failed ERCP: a multicenter international collaborative study. Gastrointest Endosc 2017; 85: $164-169$

[2] Ogura T, Nakai Y, Itoi T. Novel fine gauge electrocautery dilator for EUS-guided hepaticogastrostomy (with video). J Hepatobiliary Pancreat Sci 2019; 26: E3 -E4

\section{Bibliography}

DOI https://doi.org/10.1055/a-0965-6461

Published online: 24.7.2019

Endoscopy 2019; 51: E388-E389

(c) Georg Thieme Verlag KG

Stuttgart · New York

ISSN 0013-726X

\section{ENDOSCOPY E-VIDEOS}

https:/|eref.thieme.de/e-videos

Endoscopy E-Videos is a free ry access online section, reporting 靣辌: on interesting cases and new techniques in gastroenterological endoscopy. All papers include a high quality video and all contributions are freely accessible online.

This section has its own submission website at

https://mc.manuscriptcentral.com/e-videos 